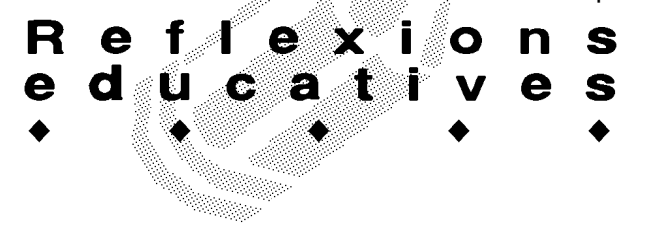

\title{
L'EDUCACIÓ FÍSICA A L'E.S.O.
}

\author{
Saturnino Gimeno, Luis Marqués, Carmen Pérez i Isabel Viscarro. Àrea de Didàctica de l'Expressió Corporal \\ José Lavilla. Professor d'Educació Física l'IES Camp Clar \\ Gemma Solé. Professora d'Educació Física al SES Mont-roig
}

\begin{abstract}
L'actual reforma de l'ensenyament obligatori ha plantejat uns reptes importants, les repercussions dels quals comencen a fer-se paleses. Tota reforma comporta uns canvis i la seva complexitat exigeix que tant els formadors de formadors com els professionals dels centres hi diguin la seva.
\end{abstract}

L'objectiu d'aquest article és fer unes reflexions sobre l'Educació Física a l'etapa de Secundària Obligatòria, concretament al primer cicle d'aquesta (12-14 anys).

Pensem que l'àrea d'Educació Física és una de les més beneficiades pel canvi de plantejaments. Està integrada en el currículum escolar amb el mateix estatus que d'altres matèries més conceptuals, amb un horari lectiu que situa l'Educació Física en igualdat de condicions amb la resta de les àrees.

Els eixos a través dels quals nosaltres centrarem l'anàlisi són: l'evolució en la formació del professorat i el disseny curricular actual i les seves implicacions.

L'Educació Física a les postrimeries del segle XX forma part dels currículums a tots els països de l'òrbita occidental. La incardinació dels continguts fisico-esportius a Espanya ha estat una tasca difícil i sempre carregada d'interès.

Des d'una serena reflexió ens adonem de l'existència de fets que influeixen en totes les manifestacions humanes.

\section{Evolució de la formació del professorat en Educació Física}

Cal recordar que la primera escola per capacitar i titular professors de gimnàstica no sorgeix per generació espontània. Amorós, marquès, secretari de Godoy i coronel, s'encarrega de transformar l'escola pestalozziana en Reial Institut amb la idea de renovar la formació del professorat.

Al 1879 Fernando de Gabriel va proposar al Congrés de Diputats que l'ensenyament de la «gimnàstica higiènica» es declarés oficial en els instituts de segona ensenyança, en les Escoles Normals, i l'Educació Física (EF a partir d'ara) obligatòria per obtenir el grau de batxillerat. Al 1881 un altre parlamentari, Manuel Becerra, va presentar una proposició de llei que, assumida pel Parlament, introdueix la creació de la primera Escola
Central de professors i professores de Gimnàstica. Per reial decret de 10 de març de 1883, s'autoritza el funcionament de l'escola, que obriria les seves portes el 1887; va funcionar set anys i va titular 87 professors i 16 professores. Malgrat l'empenta i iniciatives dels militars, amb els «gimnasios normales", l'estament civil s'anticipà tres dècades en la creació de l'escola civil.

El govern de la II República estableix el 1933 a Madrid un nou centre: l'Escola Nacional d'EF amb una doble adscripció (a la facultat de Medicina i a la secció de Pedagogia de la facultat de Filosofia i Lletres). Aturada la seva activitat durant la guerra civil, després continuaria la seva tasca fins al 1979.

A partir de 1939 el franquisme imposaria els seus criteris en formació i ensenyament. Assumeix directament la formació física i política, i encarrega la formació religiosa a l'Església. Per decret el 1942 són creades dues acadèmies, la Nacional de Mandos "José Antonio", i la "Isabel la Católica", totes dues amb el propòsit inicial de capacitar homes i dones per atendre la joventut masculina $\mathrm{i}$ femenina en els principis ideològics del règim, però amb el temps els currículums d'ambdues acadèmies s'anirien decantant cap a la formació de professors i professores d'EF.

L'any 1986 per una ordre ministerial es regula la implantació progressiva i experimental de l'EF als centres d'EGB dependents del "Ministerio de Educación y Ciencia". Després, una resolució explicitaria les instruccions per desenvolupar el programa i fer realitat l'EF als centres escolars. Així es prepara: a) la designació de professors exclusivament dedicats a la matèria; b) la seva adscripció al cicle superior; c) la normativa per a la "implantació progressiva del programa", de molta importància. Durant un llarg temps la cura de l'EF en centres docents de tota mena havia estat sota la responsabilitat compartida de les delegacions del "Movimiento" i del "Ministerio de Educación Nacional". Els canvis generals per l'establiment de la democràcia es fan amb prudència i molt a poc a poc

El professorat d'Educació Primària, en virtut de la llei 14/1970 ("General de Educación y Financiación de la Reforma Educativa") s'havia integrat a la Primera Etapa i al Cicle Superior i, pel que fa a l'EF, estava molt 


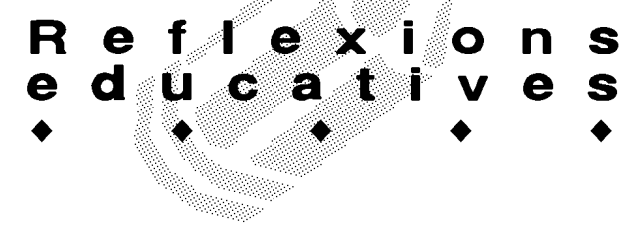

abandonada.

La Llei de Reforma Universitària (LRU 11/1983, de 25 d'agost) i la revisió dels plans d'estudis afectà les titulacions de magisteri que, amb la tornada a la titulació de mestre, comptarà amb la diplomatura, entre d'altres, de mestre especialista en Educació Física.

La LODE, d'implantació progressiva des del curs 1991/92 fins al 97/98, va fer possible la convocatòria d'oposicions per atendre l'ESO i oposicions per a llocs d'Infantil i Primària.

A la pràctica ningú no ha estat marginat. El professorat amb titulació o sense, que gaudia d'un lloc de treball en centres oficials de Secundària, ha estat confirmat com a professorat a extingir. Per oposicions s'han anat cobrint les noves necessitats amb llicenciats, i per altra banda les normes de funcionament han respectat els desitjos dels mestres que, impartint EF a l'EGB han volgut passar-se al primer tram de l'ESO. La normativa vigent indica que, per oposició, els llicenciats podran accedir al cos de professors de Secundària i que els mestres que ja hi eren podran continuar indefinidament en la mateixa situació.

Tota aquesta normativa i les decisions personals dels titulats en EF fan possible trobar-nos amb professors d'EF especialitzats en Primària, i amb mestres especialistes d'EF i llicenciats a Secundària. D'altra banda, els llicenciats s'han trobat amb el nou alumnat. Tots dos tipus de professionals (mestres i llicenciats) s'han vist immersors en la problemàtica que suposa l'ensenyament obligatori, és a dir, la permanència a les classes d'un col-lectiu indiscriminat durant molt més temps. Això ha fet que el mestre a Secundària rebi alumnes més homogeneïtzats en edat (12-14 anys) i el llicenciat treballi amb uns grups d'edats a les quals no estava acostumat (se'ls ha infantilitzat la docència).

Aquesta nova situació està propiciant la convivència de dos tipus de professionals. El mestre amb una bona formació psicopedagògica i el llicenciat amb formació més tècnica. La convivència ha estat bona i ha hagut enriquiment per a tots dos. Els primers s'han esforçat pel domini de nous camps de l'EF i els segons han fet la corresponent adaptació curricular per a adolescents que fins fa poc caminaven sota les directrius de l'Educació Primària.

El pas de mestres a la Secundària ha beneficiat I'ESO, ja que: a) estan actuant com a elements articuladors; b) segueixen desenvolupant funcions tutorials; c) han trencat la por que existia entre els pares pel canvi de centre i d'estil.

De fet el professorat d'EF a Secundària és conscient del compromís motor que han d'aconseguir dels seus alumnes, i per això dediquen temps a la preparació de la classe i són sabedors que han d'explicar el perquè i el com de les seves intervencions pedagògiques.

\section{El disseny curricular base en I'ESO: un nou enfoca- ment}

Al currículum escolar tradicionalment s'ha concedit un escàs valor educatiu a l'àrea d'Educació Física a causa, principalment, de la naturalesa del coneixement que aporta (de caràcter eminentment pràctic) que està devaluat en un model d'escola que ha prioritzat l'acumulació d'informació intel-lectual.

Actualment s'està generant una dinàmica que té com a prioritat desplegar el currículum d'Educació Física per tal que respongui al seu propi sentit, a la demanda social i a la necessitat de col-laborar en la consecució dels objectius generals de l'educació obligatòria, de l'educació integral de la persona i de la seva capacitat d'autonomia.

L'Educació Física, pel sol fet d'involucrar a més a més el cos en la seva activitat, compromet la totalitat de la persona; per tant, també la dimensió psíquica amb tots els seus components emocionals, afectius i cognitius.

A banda del canvi que es dóna a l'àrea en aquest cicle, en el plantejament i l'estructura, també hi ha un canvi significatiu en els blocs de contingut. Els anteriors programes renovats de l'Educació General Bàsica al cicle superior ens indiquen els següents blocs temàtics: Qualitats físiques, Aptituds esportives i Activitats a la natura. El que es desprèn d'aquests blocs prescriptius és bàsicament un plantejament adreçat a la iniciació i al rendiment esportius.

Com ja sabem, al nou sistema educatiu els continguts s'estructuren al voltant de tres àmbits: fets, conceptes i sistemes conceptuals; procediments; valors, actituds i normes; els quals col-laboren d'igual manera en l'adquisició de les capacitats indicades en els objectius generals de l'àrea i de l'etapa. Així doncs, l'ensenyament ha d'ocupar-se d'aquelles nocions, coneixements, hàbits, destreses, valors..., que la persona ha d'aprendre per adaptar-se al seu entorn social i cultural.

Sobre cadascun d'aquests àmbits d'experiència els alumnes han de construir aprenentatges, no tan sols de coneixement procedimental, cosa que ha caracteritzat fins fa poc temps el desenvolupament curricular de la nostra àrea, sinó que s'hi han d'incorporar i afavorir aprenentatges en relació amb el coneixement conceptual i amb el desenvolupament d'actituds, de manera que els alumnes construeixin esquemes de coneixements significatius que facin referència a l'activitat motriu i al propi cos, que facilitin tant l'adquisició de nous aprenentatges com la transferència i l'aplicació d'aquests a situacions noves i contextos diferents. 


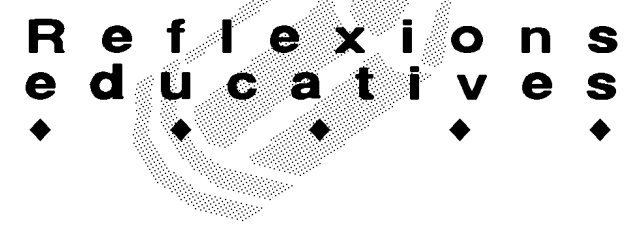

En la nostra àrea els continguts procedimentals són l'eix vertebrador del treball a desenvolupar a l'aula, amb una especial atenció a la diversitat i amb uns aprenentatges adaptats a l'àmbit motriu i a les característiques individuals i grupals dels alumnes. En aquest sentit el professor d'Educació Física es troba en una posició privilegiada per treballar una sèrie d'aspectes relacionats amb la persona: fomentar la solidaritat, el treball en equip, educar per saber acceptar l'èxit i la frustració, el sexisme, l'educació d'hàbits posturals, d'higiene, salut i nutrició. Pot afavorir la diversitat, la interrelació i la interdisciplinarietat, tant als crèdits comuns com, especialment, als crèdits variables. En definitiva, tots aquells aspectes que tenen cabuda en el que s'anomena eixos transversals de la Reforma Educativa.

Un dels avantatges de tenir un currículum semiobert és que existeix la possibilitat d'incorporar a la nostra àrea totes aquelles activitats de caire lúdico-esportiu com a resposta a la demanda social del moment. Per exemple, és possible treballar patinatge, aeròbic, esports alternatius, esports d'aventura, entre d'altres. Això fa que el professor especialista de l'àrea d'Educació Física s'hagi de preocupar per adquirir una formació permanent que li permeti estar al dia i poder donar resposta a les necessitats socials del moment.

\section{Les implicacions de l'ESO per al professor d'Educa- ció Física}

Ja hem comentat breument a l'apartat anterior quina és la situació actual del professor d'Educació Física a l'ESO, concretament al seu primer cicle, i quin ha estat el procés històric i legislatiu que ens hi ha conduït.

Ara ens centrarem en quines són les implicacions que per al professor d'Educació Física té la implantació de l'actual reforma educativa, fixant-nos ens aquells aspectes que tenen el seu origen al disseny curricular base de l'àrea d'Educació Física (DCB) creat d'acord amb la "Ley Orgánica de Ordenación General del Siste- ma Educativo" (LOGSE), aprovada a l'octubre de $1990 \mathrm{i}$ desenvolupada al Reial Decret 1345/1991, de 6 de setembre (BOE del 13), que estableix el currículum de l'ESO.

Malgrat que totes les àrees del sistema educatiu tenen els seus trets característics, no tan sols per la seva pròpia condició sinó també per la seva història 0 pel concepte que la societat en té, l'EF es troba, sens dubte, entre les que presenten clarament més trets diferencials.

La tradicional marginació de la qual ha estat objecte aquesta matèria ha estat produïda majoritàriament per un concepte dualista de la persona com a cos i ànima, on sovint el cos ha estat desvaloritzat. La regulació administrativa i educativa del sistema escolar feta a través de les diferents lleis esmentades ha contribuït a la total integració de l'EF dintre de la resta de matèries, però encara avui, sense el reconeixement i la valoració que es mereix per part de la societat.

El document oficial que es publicà al seu dia va detallar exhaustivament els principis educatius que regeixen aquesta reforma. Nosaltres destacarem aquells que considerem més significatius i que en certa manera condicionen la tasca del professor.

Aquestes implicacions serien: a) L'Educació Física s'emmarca dins del tronc comú obligatori dels dos cicles de I' ESO. b) L'horari lectiu de què es disposa, dues hores setmanals, condiciona el grau d'eficàcia de l'àrea. c) L'Educació Física forma part de l'educació integral de l'individu i per tant, s'ha d'orientar a aconseguir objectius educatius comuns, fent èmfasi en els aspectes tant perceptius i motrius com expressius, comunicatius, afectius i cognitius. d) El punt de vista explicat condicionarà els blocs de continguts, els principis didàctics i el tipus de sistema d'avaluació que haurem d'utilitzar. e) L'orientació didàctica està centrada de forma permanent en l'alumne i els seus processos d'aprenentatge, fent èmfasi en la participació activa del mateix alumne en

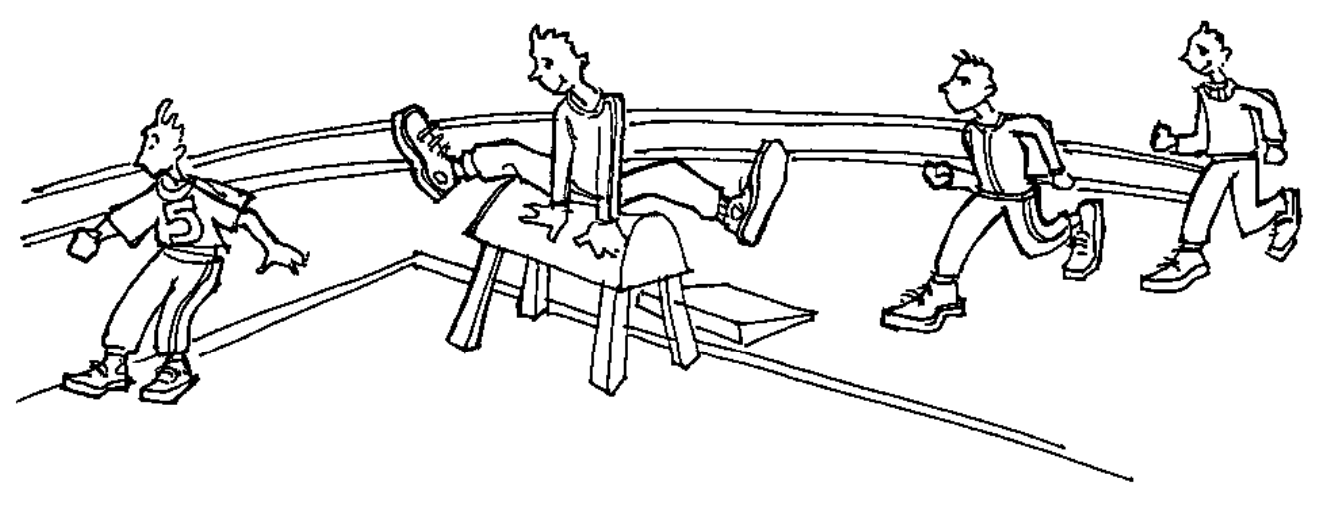




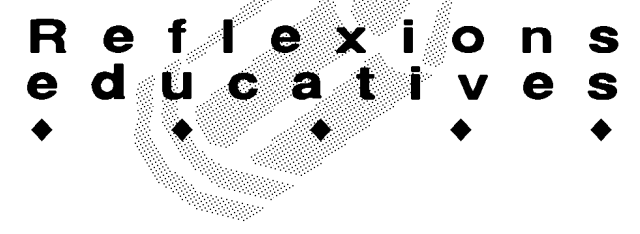

aquest procés. f) L'avaluació té caràcter continu i formatiu. Es tracta d'avaluar les capacitats de l'alumne més que no pas el seu rendiment. En aquest procés també s'inclouen la tasca pedagògica i la programació fetes pel professor.

A partir del model proposat en la reforma educativa i tenint en compte totes les implicacions citades, el professor ha anat programant la seva activitat docent, incloent-hi, a més, les orientacions que han afegit les diferents comunitats autònomes. Algunes d'aquestes orientacions didàctiques serien: a) tendència a l'autonomia de l'alumne, facilitant que prengui decisions; b) desenvolupar la seva capacitat d'aprendre per si mateix; c) afavorir al màxim la pràctica física. Per aconseguir això el professor ha d'assumir diversos rols: a) dissenyar situacions d'ensenyament que permetin rendibilitzar al màxim el temps d'aprenentatge; b) afavorir un clima positiu d'aprenentatge amb gran interacció entre l'alumne i el grup; c) avaluar la intervenció educativa; d) estructurar el desenvolupament dels continguts, de manera que s'aconsegueixi l'emancipació progressiva de l'alumne; e) oferir un sistema d'optativitat als continguts programats; f) utilitzar instruments i materials curriculars que facilitin l'aprenentatge i el desenvolupament cognitiu, motriu i actitudinal de l'alumne.

\section{Les característiques del professor}

Ja hem comentat que l'Educació Física és una matèria $a m b$ uns trets diferenciadors respecte d'altres. Aquestes diferències també les trobem en la tasca que desenvolupa el professor i que alhora ve condicionada per la seva formació acadèmica. No entrarem en detall sobre quina ha de ser la formació adient del professor, però sí farem referència a les característiques que ha de tenir per aconseguir uns bons resultats en la seva pràctica com a professional de l'ensenyament que li permetin afiançar-se en la seva tasca docent.

Segons l'opinió de Duke (1991), aquestes característiques són: a) gran expectativa professional; b) una orientació positiva quan assumeix riscos; c) obert als canvis; d) condescendent amb els experiments a les classes; e) obert davant les crítiques; f) intens coneixement dels aspectes tècnics de l'ensenyament; $g$ ) profund coneixement de la matèria; h) ser positiu davant la possibilitat d'una avaluació de la seva feina.

\section{Conclusions}

L’Educació Física a Espanya ha sofert un procés que en moltes ocasions ha estat supeditat a interessos que no responien a qüestions educatives, sinó més aviat a qüestions polítiques i religioses.

El darrer capítol d'aquest procés és el que estem vivint avui els docents dintre del marc de la Reforma i hem de dir que a l'etapa de Secundària obligatòria, en la qual hem concentrat aquest article, ha suposat uns canvis a les orientacions pedagògiques i didàctiques que han provocat que el professor d'Educació Física hagi de fer sovint un esforç considerable per adaptar-se al nou context on desenvolupa la seva tasca educativa.

En general, podem afirmar que l'àrea d'Educació Física ha sortit reforçada en alguns aspectes dintre d'aquest procés de reforma educativa. S'ha aconseguit una major equiparació amb altres matèries i un major reconeixement i valoració del professorat, entre d'altres qüestions.

D'altra banda, també ha sortit perjudicada en altres temes com la reducció del nombre d'hores lectives al primer cicle, les dificultats a l'hora d'avaluar determinades capacitats o la resistència a utilitzar certs materials didàctics per part d'alguns membres de la comunitat educativa.

Malgrat tot, estem convençuts que l'Educació Física té un àmbit de treball engrescador que el professor ha d'aprofitar i potenciar: la persona considerada de forma global, movent-se, expressant-se, comunicant-se, experimentant i creant. Només cal que veritablement es doni suport amb els recursos i els mitjans escaients perquè el professor pugui obtenir el millor de cadascun dels seus alumnes.

\section{Referències bibliogràfiques}

DUKE, D.L. Beyond minimun competence. Evaluation for professional developement. 1991. Citat per F. J. Castejón Oliva a les actes del III Congrés Nacional d'Educació Física i de Facultats d'Educació i XIV Congrés d'Escoles Universitàries de Magisteri (Pàg. 635). Universitat d'Alcalà. Guadalajara, juny de 1996.

FERNÁNDEZ NARES, S. La Educación Física en el sistema educativo español: la formación del profesorado. Univ. de Granada. Servicio de Publicaciones. Granada. 1993.

MEC. Programas Renovados de la Educación General Básica. Ciclo Superior: $6^{a}$, $7^{a}$ y $8^{a}$ curso. Editorial Escuela Española. 4aㅡ edición. Madrid. 1987.

RUIZ BERRIO, J. "La Educación del pueblo español en el proyecto de los ilustrados". Revista de Educación 88, extra (1988).

Ordre del 13 de juny de 1986, regulant la implantació progressiva i experimental de l'Educació Física als centres públics d’EGB. BOE, núm. 27.

Resolució de 21 d'octubre de 1986, de la Dirección General de Educación Básica, desenvolupant el programa d'implantació progressiva i experimental de l'Educació Física als centres públics d'EGB (BOE del 12/11/86).

Llei 14/1970 (Ley General de Educación y Financiación de la Reforma Educativa). (BOE del 6 d'agost de 1970).

Llei Orgànica de Reforma Universitària (11/1983) del 25 d'agost.

Llei Orgànica del Dret a l'Educació, LODE. Ministerio de Educación y Ciencia. «Cuadernos Legislativos». Madrid. 